\title{
Spatial and temporal monitoring of coastal water quality: refining the way we consider, gather, and interpret patterns
}

\author{
Travis S. Elsdon*, Sean D. Connell \\ Southern Seas Ecology Laboratories, School of Earth and Environmental Sciences, Darling Building DX 650418 , \\ University of Adelaide, Adelaide, South Australia 5005, Australia
}

\begin{abstract}
Environmental scientists are expected to provide interpretations about patterns across broad scales of space and time, but face the challenge that the environment can vary at smaller spatial scales than commonly recognised. We described spatial and temporal variability in nutrients and associated environmental parameters at sites associated with historical impacts to assess appropriate monitoring practices. Sites were selected on the basis of past research into nutrient-driven habitat change. Temporal variability was examined using a nested sampling design (i.e. days within weeks, weeks within months) that included monitoring nutrients and environmental parameters such as secchi depth, chlorophyll $a$, ammonia, total Kjeldahl nitrogen, total nitrogen (TN), and oxidised nitrogen. Impacted and control sites differed in nutrient concentration and Secchi depth, although sites did not differ on every sampling occasion. Impacted sites always ranked higher, based on means, in nutrient concentrations and were more turbid than control sites. In general, one impacted site had greater nutrient concentration and was more turbid than the other impacted site. Control sites typically had low and stable concentrations of TN. Variation over small time scales of days was large relative to variation at scales of weeks and months; these results warn that monitoring of long-term trends must be mindful of short-term variation and its capacity to confuse interpretations over broader time scales. In this regard, we make suggestions to improve the way we consider, gather, and interpret patterns in environmental data that almost always vary on small scales.
\end{abstract}

KEY WORDS: Water quality · Monitoring · Impacts · Management · Chlorophyll a · Turbidity • Coastal eutrophication

\section{INTRODUCTION}

Open coastal shores are often located in transitional zones where anthropogenic activities can negatively influence marine ecosystems, and managers need to identify the consequences of their policies. Many coasts are adjacent to substantial urban and industrial developments, where runoff is high in nutrients that are readily available for uptake by biological organisms. Nutrients can affect benthic reef communities by causing the growth of opportunistic turf-forming algae (Gorgula \& Connell 2004), while increases in turbidity can reduce photosynthetic capacity. Thus, understanding patterns in nutrient distribution is critical for place- ment of marine reserves (Carr et al. 2003, Roberts et al. 2003, Connell 2007) and developing baselines of data upon which future impacts can be judged (Pauly 1995, Dayton et al. 1998, Edgar et al. 2004, Connell et al. 2008). Quantifying and interpreting patterns of ambient nutrients and water clarity should therefore be a goal in coastal management.

Water monitoring programs often aim to determine changes in nutrients and environmental parameters using very few measurements to infer concentrations over lengthy periods (Grotti et al. 2001, Humborg et al. 2003, De Galan et al. 2004). Uncertainty in the variation of nutrients at each sampling period is often attributed to poor laboratory protocol in sampling accuracy 
and instrument precision (Potts 1997, Babiker et al. 2004). Although understanding the accuracy and precision of a water sample is important, especially for drinking water, monitoring programs that focus on accuracy and precision often result in heightened effort being placed on few samples (i.e. meticulous collection procedures) instead of collecting many samples. Replication of sampling gives insight into the spatial and temporal variability of patterns, a key component of understanding the process of degradation in marine systems. Monitoring programs need to be able to interpret large-scale trends in the face of small-scale variability; an issue that challenges ecologists (FowlerWalker et al. 2005).

Long-term temporal trends in ambient nutrients have been reported for many coastal areas (e.g. government monitoring agencies). Such programs are primarily interested in seasonal and annual trends, and sample water using monthly or fixed-time sampling without considering the consequences of smaller-scale change. Small-scale temporal variability, on the order of days to weeks, is rarely described in coastal waters even though it is important for understanding these ecosystems. In estuaries, several studies have shown that small-scale temporal variation in nutrients is extremely large (e.g. Caffrey et al. 2007), with changes over tidal cycles explaining up to $39 \%$ of the total variation in $\mathrm{NO}_{3}{ }^{-}$from scales of hours to decades (Caffrey et al. 2007). Such fluctuations in nutrient concentrations over short temporal scales highlight the need to understand the variability of nutrients over multiple scales if we are to reliably assess the chemical state of an aquatic system. This information would benefit monitoring programmes by indicating appropriate sampling intervals and replication to detect patterns.

Small-scale variation can easily be detected using nested or hierarchical sampling designs, which are commonly described in the literature (Morrisey et al. 1994, Quinn \& Keough 2002, Gotelli \& Ellison 2004) but less commonly used. Nested designs entail collecting data over several scales of space or time, such as collecting nutrient data at fixed sites on consecutive time scales (days, weeks, months, or seasons). These data can be analysed using ANOVA, with additional tests to determine the proportion of total variation attributed to the different scales of sampling (i.e. variance components, Vaughan \& Corballis 1969). Variance components are akin to commonly used goodness-of-fit $\left(\mathrm{r}^{2}\right)$ estimates in regressions.

The lack of information on small-scale temporal changes in environmental parameters and nutrients in coastal reefs inhibits the detection of impacts. The objective of the present study was to assess spatial and temporal variability in turbidity, chlorophyll a ( $\mathrm{chl} a)$, and nutrients at 2 biologically impacted reefs that have reduced canopy-forming algae and increased turfforming algae, and 2 reefs in good condition (Connell et al. 2008), and determine appropriate scales at which water quality monitoring should occur. Short-term temporal variation was examined using a nested sampling design that included monitoring environmental parameters and nutrients on scales of months, weeks, and days.

\section{MATERIALS AND METHODS}

Sampling sites. Four metropolitan reef sites within Gulf St Vincent, an inverse salinity gulf $150 \mathrm{~km}$ long in South Australia, Australia, were chosen for sampling. Two sites, Impacted 1 (Horseshoe) and Impacted 2 (Noarlunga), had benthic assemblages that were historically impacted by nutrient runoff, where canopyforming algae had been replaced by opportunistic turfforming algae, a process which likely reflected elevated nutrients (Gorgula \& Connell 2004, Connell et al. 2008, Gorman et al. in press). Two sites, Control 1 (Port Stanvac) and Control 2 (Moana), appeared less affected by urbanisation, as they had more extensive stands of canopy-forming algae and reduced turfforming algae, and as such were considered to be reference or control sites.

Sampling design. A nested (hierarchical) sampling design that encompassed 3 temporal scales (months, weeks, and days) was used to determine variation in environmental parameters and nutrients at all 4 sites. Sampling was done on 3 consecutive days within $3 \mathrm{wk}$ (weeks were separated by $>4 \mathrm{~d}$ ) within 3 mo (months were separated by $>10 \mathrm{~d}$ ), during the austral winter. Secchi depth was recorded and water sampled for the analysis of chl $a$, ammonia $\left(\mathrm{NH}_{3}\right)$, total Kjeldahl nitrogen ( $\mathrm{TKN}$; sum of nitrogen, ammonia, and ammonium), total nitrogen (TN), and oxidised nitrogen $\left(\mathrm{NO}_{\mathrm{x}}\right)$. Three replicate readings of secchi depth were measured on each sampling day and triplicate water samples were collected for the analysis of chl $a$ and nutrients. We chose to measure turbidity, chl $a$, ammonia, TKN, TN, and $\mathrm{NO}_{\mathrm{x}}$ because these were either cheaply and easily measured (turbidity, chl a) or good indicators of bioavailable nitrogen. TKN, TN, and $\mathrm{NO}_{\mathrm{x}}$ are also routinely analysed in monitoring studies, thus our data would be generally applicable to other systems and studies. Sampling was done at a similar tidal height, in terms of ebb and flow tide, on each day to reduce the variability due to tides, which can be large in some systems (Caffrey et al. 2007); however, we were not interested in daily fluxes in nutrients due to tides.

Turbidity was assessed as Secchi depth and was determined by lowering a $25 \mathrm{~cm}$ Secchi disc and recording the depth at which differentiation was no 
longer possible (Wetzel 1983). Chl a samples were collected in $1000 \mathrm{ml}$ bottles. Water was filtered through a Whatman GF/C filter that was stored frozen before being analysed for chl a (Wetzel 1983). Chl a was determined by resuspending GF/C filters in $10 \mathrm{ml}$ of $100 \%$ ethanol at $70^{\circ} \mathrm{C}$ for $5 \mathrm{~min}$. Samples were then cooled rapidly in ice and examined using a spectrometer at 665 and $750 \mathrm{~nm}$, using a blank of $100 \%$ ethanol. Chl a was determined using equations of Golterman et al. (1978), and was not corrected for phaeophytin.

Water samples for nutrients were collected in $250 \mathrm{ml}$ high density polyethylene (HDPE) bottles and acidified with $1 \mathrm{ml}$ of sulphuric acid: one set of bottles was filtered through a $0.45 \mu \mathrm{m}$ membrane filter $\left(\mathrm{NH}_{3}\right.$ and $\mathrm{NO}_{\mathrm{x}}$ analyses) and one was left unfiltered (TKN analysis). Powderless gloves were worn at all times and samples were stored on ice in the field and then refrigerated in the laboratory until analysed; all analyses were completed within $28 \mathrm{~d}$ of sample collection. Nutrient samples were analysed at Australian Laboratory Services, Melbourne, using an Aquakem discrete analyser (Thermo Scientific). Ammonia was analysed based on a Berthelot reaction (method: APHA 4500- $\mathrm{NH}_{3} \mathrm{H}$ ). TKN was analysed based on the standard block digestion for organic nitrogen (method: APHA 4500- $\mathrm{N}_{\text {org }} \mathrm{D}$ ). Oxidised nitrogen was analysed via cadmium reduction (method: APHA 4500- $\mathrm{NO}_{3}{ }^{-} \mathrm{I}$ ). Total nitrogen was calculated as the sum of $\mathrm{NO}_{\mathrm{x}}$ and TKN. Limits of detection (LOD) and average reproducibility (spiked recovery) were: $\mathrm{NH}_{3}, 0.01 \mathrm{mg} \mathrm{l} \mathrm{l}^{-1}, 97.7 \%$; TKN, $0.1 \mathrm{mg} \mathrm{l}^{-1}$, $97.8 \%$; TN, $0.1 \mathrm{mg} \mathrm{l}^{-1}$; and $\mathrm{NO}_{\mathrm{x}}, 0.01 \mathrm{mg} \mathrm{l} \mathrm{l}^{-1}, 97.5 \%$.

Statistics. Univariate ANOVA was used to determine if parameters (turbidity, chl $a$, and nutrients) differed over time and between sites. Four-factor ANOVA tested for differences among sites and time scales for each parameter. The ANOVA model consisted of the factor Site orthogonal to the temporal scales, which were all random and nested within each other (i.e. Day within Week, Week within Month)(Quinn \& Keough 2002). Analyses were presented for the cases where Site was treated as fixed and random (see Table 1). We recommend Underwood (1997) as a text for considering ANOVA models that combine both nested scales of space and time.

Three-factor ANOVAs tested for differences among time scales for each parameter, and were presented with estimates of components of variation (Vaughan \& Corballis 1969), to determine which of the temporal scales contributed most to the observed variation in turbidity, chl $a$, and nutrients. For all tests, where significant differences were detected between sampling times (e.g. p $<0.05$, or $\mathrm{p}<0.01$ if heterogeneous), the means were statistically compared post hoc using Student-Newman-Keuls (SNK) tests to determine where differences occurred (Quinn \& Keough 2002).

\section{RESULTS}

\section{Spatial scale tests}

Site and Day interacted for the parameters of turbidity, chl $a, \mathrm{TN}, \mathrm{NO}_{\mathrm{x}}$, and $\mathrm{NH}_{3}$, indicating that differences were detected among sites but not for every sampling day. Interactions of Site and Week were detected for all parameters except chl $a$, again indicating different patterns among sites on different weeks.

Turbidity was consistently greater at Impacted 1 and/or Impacted 2 compared to the 2 control sites, with this pattern being consistent for 25 of $27 \mathrm{~d}$ (Site $\times$ Day interaction, Table 1, Fig. 1). The pattern did, however, vary between sampling days whereby Impacted 1 and Impacted 2 were different from one another. Greater differences between sites were detected in some weeks (i.e. Week 1 of Month 2) compared to others (Site $\times$ Week interaction). Mean and median secchi

Table 1. ANOVA mean squares (MS) for spatial and temporal scale differences in turbidity, chlorophyll $a$, total Kjeldahl nitrogen (TKN), total nitrogen (TN), oxidised nitrogen $\left(\mathrm{NO}_{\mathrm{x}}\right)$, and ammonia $\left(\mathrm{NH}_{3}\right)$ among 4 sites where Site is treated as a fixed factor. Where Site is treated as a random factor, all MS remain the same, except the main effects of Months and Weeks have no associated test. Data was $\ln (\mathrm{x}+1)$ transformed. Where Cochran's $C$-test was $\mathrm{p}<0.05$ after transformation, significance was judged at $\alpha=0.01$, otherwise significance was judged at $\alpha=0.05{ }^{* *}: \mathrm{p}<0.01,{ }^{* * *}: \mathrm{p}<0.001$. Table 3 provides site-specific tests across nested time-scales

\begin{tabular}{|c|c|c|c|c|c|c|}
\hline Source of variation & Turbidity & Chl a & TKN & TN & $\mathrm{NO}_{\mathrm{x}}$ & $\mathrm{NH}_{3}$ \\
\hline Site & $3.9347^{* * *}$ & 1.4476 & 0.1723 & $2.3025^{* * *}$ & $1.9936^{* * *}$ & $0.2821^{* * *}$ \\
\hline Month & 3.8518 & 4.4148 & $0.7377^{* *}$ & 0.4926 & 0.0466 & 0.0281 \\
\hline Week (Mo) & $3.4585^{* * *}$ & $1.9694^{* *}$ & $0.0528^{* * *}$ & $0.1252^{* * *}$ & 0.0516 & $0.0565^{* * *}$ \\
\hline Day [(Wk)Mo] & $0.1863^{* * *}$ & $0.4784^{* * *}$ & $0.0071^{* *}$ & 0.0160 & $0.0167^{* *}$ & $0.0059^{* * *}$ \\
\hline Site $\times$ Month & 0.1332 & 0.7293 & 0.0237 & 0.0157 & 0.0062 & 0.0008 \\
\hline Site $\times$ Week $(\mathrm{Mo})$ & $0.1057^{* * *}$ & 0.2537 & $0.0133^{* * *}$ & $0.0574^{* * *}$ & $0.0402^{* *}$ & $0.0320^{* * *}$ \\
\hline Site $\times$ Day $[(\mathrm{Wk}) \mathrm{Mo}]$ & $0.0392^{* * *}$ & $0.2637^{* * *}$ & 0.0041 & $0.0171^{* *}$ & $0.0147^{* * *}$ & $0.0054^{* * *}$ \\
\hline Error & 0.0146 & 0.0616 & 0.0034 & 0.0092 & 0.0075 & 0.0005 \\
\hline
\end{tabular}




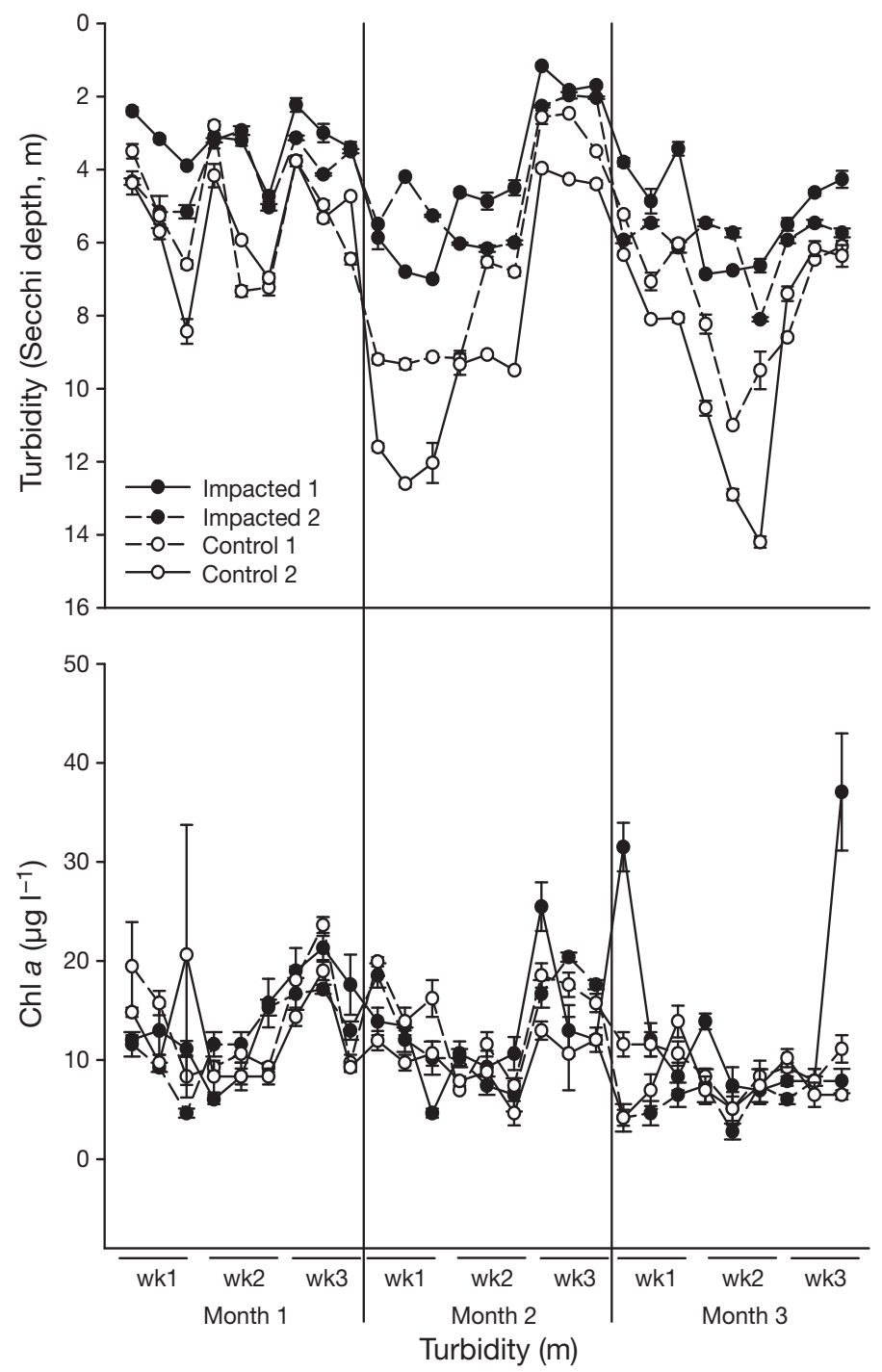

Fig. 1. Turbidity (Secchi depth) and chlorophyll a measurements at impacted and control sites, collected on replicate days, within weeks, within 3 mo. Values are means \pm SE

depths were greater at control sites compared to impacted sites (Table 2), and on no sampling days were impacted sites greater than control sites. Chl a differed among sites for 20 of 27 d (Site $\times$ Day interaction, Table 1, Fig. 1). Similarly, mean chl a concentrations gave little indication of substantial differences among sites, and no trends were apparent in mean and median values between impacted and control sites (Table 2).

Concentrations of oxidised nitrogen were greater at Impacted 1 compared to all other sites for 26 of $27 \mathrm{~d}$ (Table 1, Fig. 2). Impacted 1 had consistently higher $\mathrm{NO}_{\mathrm{x}}$ values over the period of weeks compared to other sites (Site $\times$ Week interaction). Concentrations of ammonia were greater at Impacted 1 compared to all other sites, which were all similar (Table 1, Fig. 2). This
Table 2. Mean, median, minimum (Min) and maximum (Max) of parameters at each site. LOD: limit of detection, for $\mathrm{NO}_{\mathrm{x}}$ and ammonia, this is $0.01 \mathrm{mg} \mathrm{l}^{-1}$, for total Kjeldhal nitrogen and total nitrogen, $0.1 \mathrm{mg} \mathrm{l}^{-1}$. All parameters are expressed in units of $\mathrm{mg}^{-1}( \pm \mathrm{SE})$ except turbidity, which is in $\mathrm{m}( \pm \mathrm{SE})$

\begin{tabular}{|c|c|c|c|c|}
\hline $\begin{array}{l}\text { Parameter } \\
\text { Site }\end{array}$ & Mean & Median & Min & Max \\
\hline \multicolumn{5}{|l|}{ Turbidity } \\
\hline Impacted 1 & $4.23 \pm 0.19$ & 4.20 & 1.10 & 7.00 \\
\hline Impacted 2 & $4.81 \pm 0.16$ & 5.30 & 1.80 & 8.20 \\
\hline Control 1 & $6.48 \pm 0.26$ & 6.60 & 2.20 & 11.10 \\
\hline Control 2 & $7.64 \pm 0.34$ & 6.90 & 3.50 & 14.50 \\
\hline \multicolumn{5}{|c|}{ Chlorophyll a } \\
\hline Impacted 1 & $13.71 \pm 0.89$ & 11.12 & 4.17 & 48.65 \\
\hline Impacted 2 & $10.55 \pm 0.57$ & 9.73 & 1.39 & 20.85 \\
\hline Control 1 & $12.44 \pm 0.57$ & 11.12 & 2.78 & 27.80 \\
\hline Control 2 & $9.99 \pm 0.63$ & 8.34 & 2.78 & 46.57 \\
\hline \multicolumn{5}{|l|}{$\mathrm{NO}_{\mathrm{x}}$} \\
\hline Impacted 1 & $0.43 \pm 0.03$ & 0.46 & LOD & 1.04 \\
\hline Impacted 2 & $0.05 \pm 0.02$ & 0.02 & LOD & 1.53 \\
\hline Control 1 & $0.03 \pm 0.01$ & 0.02 & LOD & 0.35 \\
\hline Control 2 & $0.02 \pm 0.00$ & 0.02 & LOD & 0.07 \\
\hline \multicolumn{5}{|l|}{ Ammonia } \\
\hline Impacted 1 & $0.20 \pm 0.02$ & 0.17 & LOD & 0.77 \\
\hline Impacted 2 & $0.06 \pm 0.00$ & 0.06 & LOD & 0.25 \\
\hline Control 1 & $0.05 \pm 0.00$ & 0.06 & LOD & 0.10 \\
\hline Control 2 & $0.06 \pm 0.00$ & 0.06 & LOD & 0.14 \\
\hline \multicolumn{5}{|c|}{ Total Kjeldahl nitrogen } \\
\hline Impacted 1 & $0.31 \pm 0.02$ & 0.30 & LOD & 0.80 \\
\hline Impacted 2 & $0.19 \pm 0.01$ & 0.20 & LOD & 0.50 \\
\hline Control 1 & $0.19 \pm 0.01$ & 0.20 & LOD & 0.80 \\
\hline Control 2 & $0.19 \pm 0.01$ & 0.20 & LOD & 0.70 \\
\hline \multicolumn{5}{|c|}{ Total nitrogen } \\
\hline Impacted 1 & $0.73 \pm 0.04$ & 0.70 & LOD & 1.60 \\
\hline Impacted 2 & $0.23 \pm 0.02$ & 0.20 & LOD & 1.50 \\
\hline Control 1 & $0.21 \pm 0.01$ & 0.20 & LOD & 0.80 \\
\hline Control 2 & $0.20 \pm 0.01$ & 0.20 & LOD & 0.70 \\
\hline
\end{tabular}

pattern was detected for 16 of 27 d (Site $\times$ Day interaction) and 5 of $9 \mathrm{wk}$ (Site $\times$ Week interaction). The remaining days and weeks showed no difference in concentration among sites. On no sampling occasion did control sites have greater ammonia concentrations than Impacted 1.

TKN concentrations at Impacted 1 was greater than all other sites for 4 of 9 wk (Impacted $1>\operatorname{Impacted} 2=$ Controls). There was $1 \mathrm{wk}$ where Impacted 2 was lower than all other sites, however, this exception was largely caused by $1 \mathrm{~d}$ (Site $\times$ Week interaction, Table 1 , Fig. 3). TN was greatest at Impacted 1 compared to all other sites for 22 of $27 \mathrm{~d}$ and 8 of $9 \mathrm{wk}$ (Site $\times$ Day and Site $\times$ Week interactions, Table 1, Fig. 3). For $1 \mathrm{~d}$ both impacted sites were greater than control sites (Impacted $1=$ Impacted $2>$ Controls). Mean and median $\mathrm{NO}_{\mathrm{x}}$, ammonia, $\mathrm{TKN}$, and TN were greatest at Impacted 1 compared to all other sites (Table 2). 


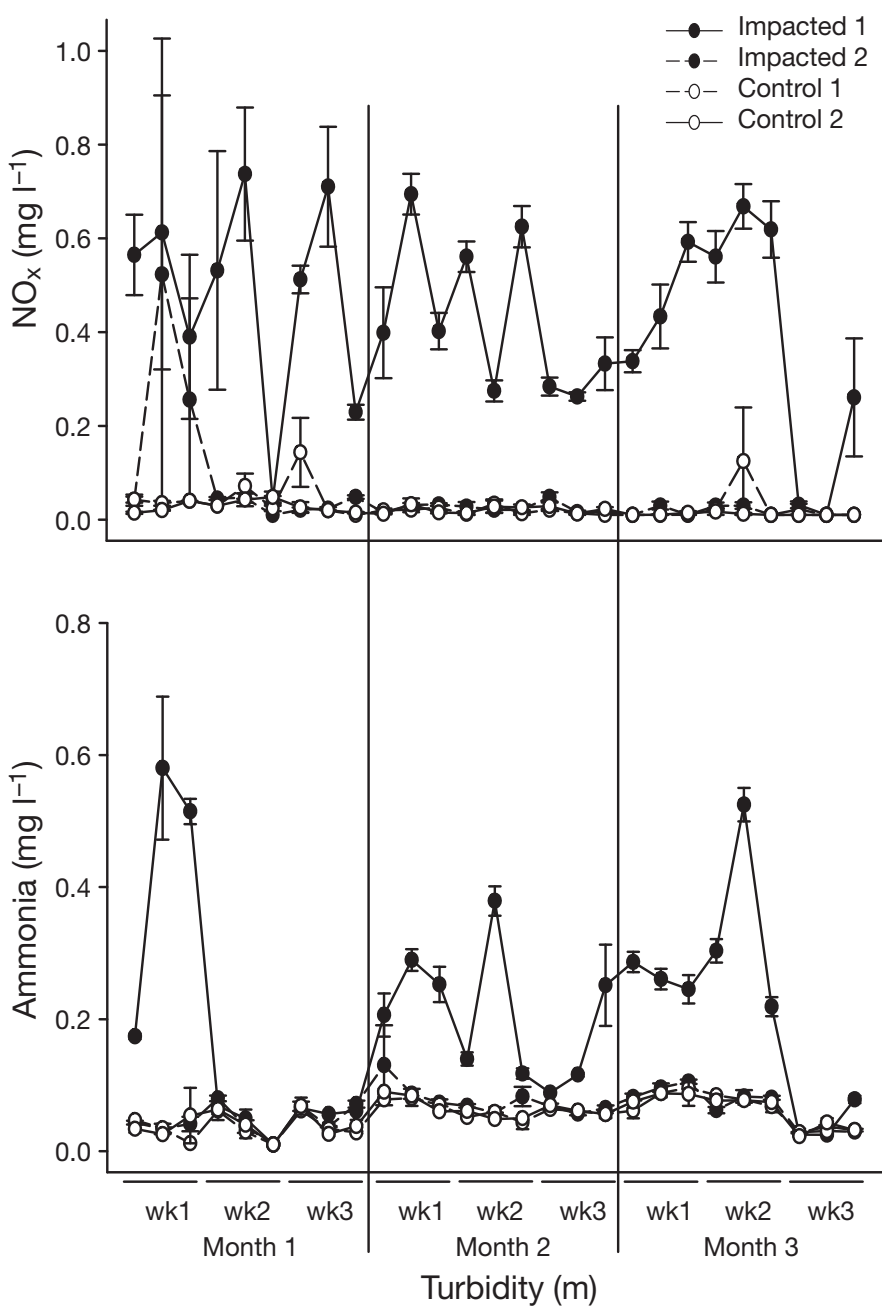

Fig. 2. Oxidised nitrogen $\left(\mathrm{NO}_{\mathrm{x}}\right)$ and ammonia concentrations at impacted and control sites, collected on replicate days, within weeks, within 3 mo. Values are means \pm SE

\section{Temporal scale tests}

Turbidity varied significantly on the temporal scales of days and weeks at each of the 4 sites (Table 3, Fig. 1). Differences among weeks were detected during the second month for all sites, as well as the first month for Impacted 2. Differences on the scale of weeks accounted for 57.8 to $86.1 \%$ of the total variability in turbidity, and Impacted 1 and Control 2 had the greatest variability. Turbidity varied on temporal scales of days at all sites, because replicate days of sampling often had different water clarity. The variability attributed to daily scales ranged from 10.5\% (Impacted 1) to $25.1 \%$ (Control 1).

$\mathrm{Chl}$ a varied on temporal scales of weeks (Impacted 2 and Control 1) and days (Impacted 1, Impacted 2, and Control 1) (Table 3, Fig. 1). No differences were detected at Control 2. Variation among replicate weeks occurred during the second month of sampling, when the second week had higher concentrations than the first and third weeks in that month. Weekly variation accounted for $35.9 \%$ of variation at Impacted 2 and $34.7 \%$ at Control 1. Variation among replicate days was detected for 3, 4, and 6 wk at Control 1, Impacted 2, and Impacted 1, respectively, and accounted for 16.8 to $83.3 \%$ of the total variability in chl $a$.

$\mathrm{NO}_{\mathrm{x}}$ varied on scales of months (Control 2), weeks (Impacted 2), and days (Impacted 1) (Table 3, Fig. 2). Control 2 had lower mean concentrations of $\mathrm{NO}_{\mathrm{x}}$ in the first month, followed by the second and then third months (mean $\pm \mathrm{SE}_{\text {; }}$ Month $1=0.012 \pm 0.00$, Month $2=$ $0.021 \pm 0.02$, Month $3=0.028 \pm 0.00 \mathrm{mg} \mathrm{l}^{-1}$ ); however, results of the SNK test were ambiguous and failed to detect significant differences among months. Monthly variation accounted for $29.1 \%$ of the total variation in

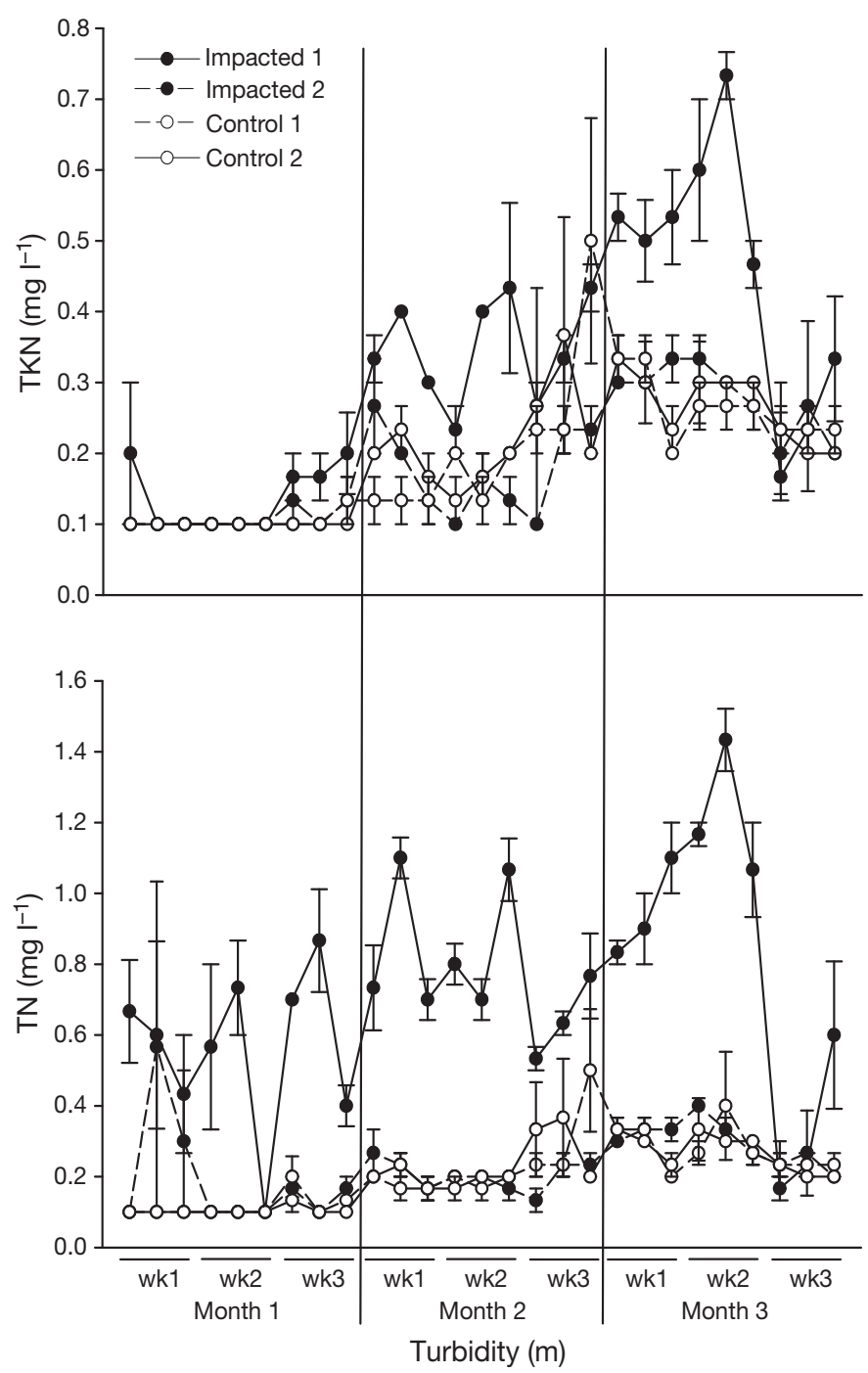

Fig. 3. Total Kjeldahl nitrogen (TKN) and total nitrogen (TN) concentrations at impacted and control sites, collected on replicate days, within weeks, within 3 mo. Values are means \pm SE 
$\mathrm{NO}_{\mathrm{x}}$ at Control 2. Weekly variation at Impacted 2 occurred only in the first month and accounted for $11.1 \%$ of the total variation. Daily variation at Impacted 1 was detected during 3 weeks and accounted for $32.9 \%$ of total variation.

Ammonia varied on scales of weeks (all sites), and days (Impacted 1 and Control 1) (Table 3, Fig. 2). Weekly variation at each site was detected during the third month, and at Impacted 1 in the first month; this weekly variation represented between 33.1 to $60.7 \%$ of the total variation in ammonia. Daily variation at Impacted 1 and Control 1 was detected within 4 random weeks at both sites and accounted for 32.2 and $24.5 \%$ of the total variability, respectively.

TKN varied on scales of months (Impacted 1, Impacted 2, Control 2), weeks (Impacted 1, Control 2), and days (Impacted 1) (Table 3, Fig. 3). No differences in TKN were detected at Control 1. Monthly variation was observed, but was inconsistent among sites. At Impacted 1 differences were detected among all 3 mo (Month $1<$ Month $2<$ Month 3), at Impacted 2 the third month differed (Month 1 = Month $2<$ Month 3), and at Control 2 the first month differed (Month $1<$ Month 2 $=$ Month 3). Monthly variation accounted for between 41.9 to $57.7 \%$ of the total variation in TKN. Weekly variation at Impacted 1 occurred in the third month only, while at Control 2 differences among weeks were detected in the second and third months. Weekly variation accounted for 24.0 and $8.9 \%$ of the total variation at Impacted 1 and Control 2, respectively. Daily variation at Impacted 1 occurred only within one week, and represented $7.2 \%$ of the total variation.

TN varied with months (Control 2), weeks (Control 2, Impacted 1), and days (Impacted 1) (Table 3, Fig. 3). No variation was detected at Impacted 2 and Control 1. Monthly variation at Control 2 occurred because the first month had lower concentrations than the others (Month $1<$ Month 2 = Month 3); this variation accounted for $43.4 \%$ of the total variation in $\mathrm{TN}$. Weekly variation at Impacted 1 occurred in the third month, and at Control 2 in the second and third months; weekly variation accounted for $47.2 \%$ of the total variation at Impacted 1 and $10.8 \%$ at Control 2. Daily variation at Impacted 1 occurred in 3 weeks, one week within each month, and accounted for $22.4 \%$ of the total variation in $\mathrm{TN}$.

\section{Regressions}

TN and $\mathrm{NO}_{\mathrm{x}}$ were positively correlated for 3 of the 4 sites (not for Control 1) and for the entire dataset $(y=$ $\left.0.667 x-0.094, r^{2}=0.7695\right)$. No correlations between other variables were detected.

Table 3. ANOVA mean squares for temporal scale differences in turbidity, chlorophyll $a$, total Kjeldahl nitrogen (TKN), total nitrogen (TN), oxidised nitrogen $\left(\mathrm{NO}_{\mathrm{x}}\right)$, and ammonia $\left(\mathrm{NH}_{3}\right)$ for each of 4 sites. The proportion of variation attributed to each time scale is expressed as \% V

\begin{tabular}{|c|c|c|c|c|c|c|c|c|c|c|c|c|}
\hline \multirow{2}{*}{$\begin{array}{l}\text { Source of } \\
\text { variation }\end{array}$} & \multicolumn{2}{|c|}{ Turbidity } & \multicolumn{2}{|c|}{ Chl a } & \multicolumn{2}{|l|}{$\mathrm{NO}_{\mathrm{x}}$} & \multicolumn{2}{|l|}{$\mathrm{NH}_{3}$} & \multicolumn{2}{|c|}{ TKN } & \multicolumn{2}{|l|}{ TN } \\
\hline & MS & $\% \mathrm{~V}$ & MS & $\% \mathrm{~V}$ & MS & $\% \mathrm{~V}$ & MS & $\% \mathrm{~V}$ & MS & $\% \mathrm{~V}$ & MS & $\% \mathrm{~V}$ \\
\hline \multicolumn{13}{|l|}{ Impacted 1} \\
\hline Week (Mo) & $25.4396^{* * *}$ & * 86.1 & 0.7260 & 0.0 & 0.1460 & 23.8 & $0.1434^{* * *}$ & 60.7 & $0.1095^{* * *}$ & 24.0 & $0.6895^{* *}$ & 47.2 \\
\hline Day [(Wk)Mo] & $1.0821^{* * *}$ & 10.5 & $0.6439^{* * *}$ & 83.3 & $0.0507^{* * *}$ & 32.9 & $0.0201^{* * *}$ & 32.2 & $0.0167^{*}$ & 7.2 & $0.1289^{* * *}$ & 22.4 \\
\hline Error & 0.0893 & 2.8 & 0.0464 & 16.7 & 0.0151 & 43.3 & 0.0012 & 7.1 & 0.0074 & 17.2 & 0.0401 & 30.4 \\
\hline \multicolumn{13}{|l|}{ Impacted 2} \\
\hline Week (Mo) & $0.6401^{* * *}$ & 57.8 & $120.1957^{* *}$ & 35.9 & $0.0245^{*}$ & 11.1 & $0.0037^{* *}$ & 33.1 & 0.0079 & 6.0 & 0.0220 & 8.6 \\
\hline Day [(Wk)Mo] & $0.0425^{* * *}$ & * 19.6 & $19.5834^{* * *}$ & 16.8 & 0.0071 & 0.0 & 0.0008 & 15.0 & 0.0033 & 2.2 & 0.0092 & 0.0 \\
\hline Error & 0.0012 & 1.7 & 3.8881 & 12.5 & 0.0132 & 87.3 & 0.0004 & 45.2 & 0.0026 & 34.1 & 0.0130 & 87.4 \\
\hline \multicolumn{13}{|l|}{ Control 1} \\
\hline Month & $1.0459^{\mathrm{a}}$ & 0.0 & 1.1241 & 9.6 & $0.0051^{\mathrm{a}}$ & 4.82 & 0.0068 & 20.11 & $0.1245^{\mathrm{a}}$ & 36.7 & $0.1282^{\mathrm{a}}$ & 35.3 \\
\hline Week (Mo) & $1.0124^{* * *}$ & * 65.6 & $0.7246^{*}$ & 34.7 & 0.0015 & 0.0 & $0.0031^{* *}$ & 40.76 & 0.0186 & 16.0 & 0.0146 & 8.6 \\
\hline Month & 1.28 & 5.1 & $1.30^{\mathrm{a}}$ & 12.0 & $0.0019^{\mathrm{a} *}$ & 29.09 & $0.0049^{a}$ & 12.56 & $0.1370^{\mathrm{a} * *}$ & 41.9 & $0.1411^{\mathrm{a} * *}$ & 43.4 \\
\hline Week (Mo) & $0.99^{* * *}$ & 81.1 & 0.41 & 10.3 & 0.0003 & 5.45 & $0.0025^{* *}$ & 33.17 & $0.0095^{* *}$ & 8.9 & $0.0111^{* *}$ & 10.8 \\
\hline Day [(Wk)Mo] & $0.07^{* * *}$ & 12.6 & 0.22 & 6.7 & 0.0002 & 16.37 & 0.0006 & 13.57 & 0.0023 & 0.0 & 0.0024 & 0.0 \\
\hline Error & 0.00 & 1.2 & 0.10 & 71.0 & 0.0001 & 49.09 & 0.0003 & 40.70 & 0.0043 & 49.2 & 0.0038 & 45.8 \\
\hline
\end{tabular}




\section{DISCUSSION}

\section{Spatial variation}

Differences were observed among sites in turbidity, chl $a$, and nutrient concentrations. Although sites did not differ on every sampling occasion, generally impacted sites had greater nutrients and were more turbid than control sites. Differences between Impacted 1 and all other sites may be due to the former's location: Impacted 1 was located approximately $1 \mathrm{~km}$ from a wastewater treatment plant where effluent is discharged at a rate of $190 \mathrm{t} \mathrm{yr}^{-1}$ of nitrogen, of which $39 \mathrm{t}$ is readily bioavailable ammonia (www.npi.gov.au), and adjacent to a creek that intermittently discharges terrestrial pollutants.

Spatial patchiness in nutrients, turbidity, and chl a have been commonly described in both coastal regions (Boyer et al. 1997, Gibbs 2000) and estuaries (Li \& Smayda 2001, Huang et al. 2003). Changes in nutrients, turbidity, and chl a occur at scales of $\mathrm{m}$ (Grenz et al. 2000, Seuront et al. 2002) to km (Boyer et al. 1997), with changes reflecting water mass differences and boundary flows (Gibbs 2000) as well as land-use (Gorman et al. in press). The ability to detect spatial patterns may not be clear from sampling on a single day; however, analysis across multiple days of data may provide more confident interpretations for their existence. The present study highlights that replicating water collections can improve the detection of spatial patterns in water quality needed to assess the drivers of benthic change (Connell et al. 2008).

\section{Temporal variation}

In the present study, turbidity and chl a varied on short time scales of weeks and days. For turbidity, greater variation was found at the longer temporal scales, indicating that daily variation was less important than differences among weeks. This was not, however, always the case for chl $a$, where daily variation was considerable.

Consistency between the temporal scales of change in the present study and the literature are difficult to evaluate, due to few studies examining turbidity and chl a using nested sampling designs. Generally, studies that examine turbidity and chl a do so using few (single) sampling times to describe the concentration of nutrients for a month or season (White et al. 2004). Chl a has been observed to change over tidal cycles in estuaries (Li \& Smayda 2001) as well as longer periods of time such as months and seasons (Greene \& Beechie 2004, White et al. 2004, Brodie et al. 2007), including periodical seasonality in chl a concentrations at Im- pacted 2 (South Australia Environmental Protection Authority [EPA] unpubl. data). Changes in nutrients that occur over short time scales, such as tides, are most likely to represent water body mixing and smallscale nutrient use by suspended algae. Longer-scale changes are likely to be due to cycling of productivity (related to increased soluble nutrient availability), changes in light climate and day length, and water temperatures during different seasons. We found no correlations between turbidity or chl a and environmental parameters (i.e. salinity) or nutrients, suggesting that differences we detected in the present study were predictable via more routinely monitored parameters.

Across all sites $\mathrm{NO}_{\mathrm{x}}$ and $\mathrm{NH}_{3}$ varied at different temporal scales. For $\mathrm{NO}_{\mathrm{x}}$, temporal variation appeared minimal, with the exception of concentrations at Impacted 1, which were variable on daily scales, which suggested that variation at small temporal scales is important. For $\mathrm{NH}_{3}$, variation at larger temporal scales was more important than variation at smaller temporal scales.

Many studies have investigated temporal variation in $\mathrm{NO}_{\mathrm{x}}$ and $\mathrm{NH}_{3}$ in both estuarine and coastal waters, on decadal to tidal time scales (Neal et al. 2000, Grotti et al. 2001, De Galan et al. 2004, Ensign \& Paerl 2006, Caffrey et al. 2007). Few studies have, however, examined the variation attributed to different temporal scales within a single system. Caffrey et al. (2007) calculated variation attributed to scales from decadal to daily and tidal influences, and concluded that tidal variation explained 39\% and diurnal variation $15 \%$ of the total variation in $\mathrm{NO}_{3}{ }^{-}$ within a semi-enclosed estuary. Thus, variation on scales of $\leq 1 \mathrm{~d}$ was responsible for $54 \%$ of the total variation in $\mathrm{NO}_{3}{ }^{-}$. Several studies have also reported means and variance estimates (commonly SD) for different temporal scales (e.g. Grotti et al. 2001, Buzzelli et al. 2004, De Galan et al. 2004). These studies found that variation around a mean (i.e. SD) was equal to or larger than differences among sampling times (Grotti et al. 2001, Buzzelli et al. 2004, De Galan et al. 2004), suggesting that variation within a sampling period is large, and a greater emphasis on collecting samples over short time scales (i.e. sampling multiple days) is required to obtain accurate estimates and deduce temporal trends over short time frames (months). Given the large variation we found at smaller temporal scales, our results suggest that small-scale variation predominates in coastal systems.

We found no correlations with $\mathrm{NO}_{\mathrm{x}}$ or $\mathrm{NH}_{3}$ and any environmental parameter (i.e. turbidity, chl a). Correlations between $\mathrm{NO}_{\mathrm{x}}$ and $\mathrm{NH}_{3}$ and salinity have been described (decreased concentrations with increased salinity) (White et al. 2004, Cox et al. 2006), however, these parameters were not related to temperature, $\mathrm{pH}$, or turbidity (White et al. 2004). Negative 
correlations with salinity most likely reflect mixing of water bodies and not necessarily that freshwater contains higher nitrogen and $\mathrm{NH}_{3}$ concentrations, as Cox et al. (2006) and Caffrey et al. (2007) found no relationship with freshwater inputs.

TKN varied on the scales of months, weeks, and days at the impacted sites and Control 2. Variation in TKN at large temporal scales was more important, indicating trends in the dataset among different months. TN varied with months, weeks, and days, and like TKN, larger temporal scales were more important, indicating that TN was temporally more consistent within a site than other nutrients. Literature suggests that TKN can vary with seasons (Boyle et al. 2004) and months (EPA 2008), with differences often detected among consecutive (monthly) sampling times (EPA 2008). From the limited data available for TN, temporal variation appears less than that for other nutrients (TKN, $\mathrm{NO}_{\mathrm{x}}$ etc.), with values collected in consecutive months being largely of the same magnitude (EPA 2008). TKN and TN did not correlate to any environmental parameters, suggesting that sampling of nutrients, turbidity, and chl a may not always be useful as proxies for ambient nitrogen concentrations.

\section{Sampling benefits and recommendations}

Understanding changes in nutrients and environmental parameters in coastal environments is a prerequisite in monitoring programs that aim to determine changes in concentrations. Analysis of spatial patterns dominate ecological studies, and there is a particular need to determine the consistency of patterns from one particular place to another, both locally (on the scale of $\mathrm{m}$ to $\mathrm{km}$ ) and regionally (on the scale of 1000s of $\mathrm{km}$ ) (Underwood \& Petraitis 1993, Huston 1999, FowlerWalker et al. 2005). Studies that examine changes in nutrients often concentrate on spatial patterns to obtain generality for an area (Gibbs 2000, Grotti et al. 2001). Temporal changes in nutrients have also been examined in order to determine patterns over time. In general, studies that claim to address temporal scales of nutrients in aquatic systems often do so by examining trends in monthly and/or seasonal sampling, where few samples are taken to represent lengthy periods of time (Fock 2003, Buzzelli et al. 2004, Brodie et al. 2007). Short-term changes in nutrients can cause confusion when trying to interpret long-term trends in datasets. If short-term changes in nutrients are large, then changes detected using monthly and/or seasonal sampling may not accurately reflect changes over smaller temporal scales (reflecting weeks or days) which can be the result of processes of land runoff, rain events, and tidal mixing (but see Caffrey et al. 2007).
Sampling of nutrients using a nested design can highlight the magnitude of change within systems among alternative scales of observation (Morrisey et al. 1992, Hatje et al. 2001), and when coupled with statistics such as variance components (Vaughan \& Corballis 1969, Graham \& Edwards 2001), can identify relevant scales of variation. In the present study, month, weeks within months, and days within weeks were chosen to give estimates of changes in nutrients at several sites across a broad time scale. We observed substantial variation across short temporal scales relative to that at longer scales. Thus to detect patterns over large periods (months, seasons) it would be advantageous to collect water on several replicate days rather than a single day, the average of which would give a more statistically precise estimate of the mean for that period of interest. This more sophisticated type of sampling has been previously used by ArandaCirerol et al. (2006) in long-term monitoring of nutrients. The number of sampling times required is dependent on the sample variability of the nutrient or environmental parameter. Nutrients with substantial variation at small scales (i.e. $\mathrm{NO}_{\mathrm{x}}, \mathrm{NH}_{3}$ ) require a greater number of sampling days to determine patterns compared to more stable nutrients, such as TKN. Importantly, sampling protocols should be consistent between areas if patterns are to be compared between sites.

What nutrients or environmental parameters should be analysed? The answer to this question depends on the spatial and temporal variation of the parameter, as well as the question being addressed. If a study aims to identify differences among sites, for example potentially impacted and control sites, then the choice of parameter should centre on those that are less temporally variable, but vary predictably in space. In the present study, nutrients that displayed good spatial variation were $\mathrm{NO}_{\mathrm{x}}$ and $\mathrm{TN}$. If the aim is to monitor changes at one site over time, then parameters that show temporal changes over moderate scales may be useful, such as chl $a$, turbidity, and TKN. The biological significance of different parameters requires consideration. For example, $\mathrm{NH}_{3}$ and $\mathrm{NO}_{\mathrm{x}}$ were highly variable in the present study, but gave a good indication of the nutrients that are readily available for plants and algae; as such they are vital in understanding eutrophication processes. Nutrients that are dynamic, i.e. large changes over temporal scales of days, may not be ideally suited to long-term monitoring of temporal variation, as differences due to the day of sampling may affect long-term trends.

To exemplify the influence of variation on long-term interpretations of trends, we can examine data collected previously from Impacted 2 as part of routine monthly sampling by the EPA with data from the pre- 


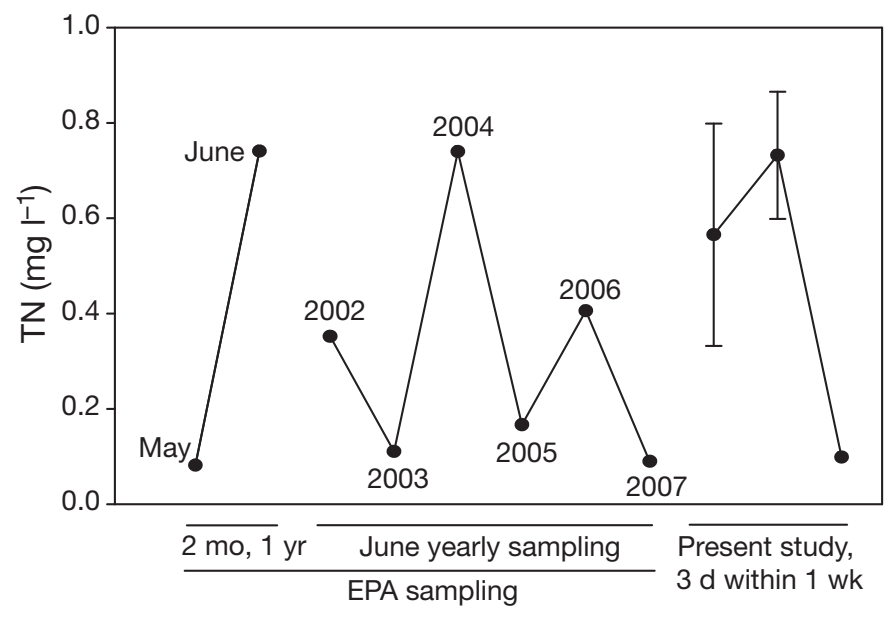

Fig. 4. Comparison of total nitrogen (TN) concentration between samples collected monthly as part of routine Environmental Protection Authority (EPA) sampling and samples collected daily from the present study

sent study. EPA sampling was done once per month, and differences in nutrients among samples were interpreted as monthly or annual trends (Fig. 4) (EPA 2008). In the present study, however, we found that differences among replicate days were as large as the differences the EPA detected among months and years (Fig. 4). Thus, interpreting monthly trends from sampling $1 \mathrm{~d}$ only, and disregarding short-term variability, may result in misinterpretations of trends. For this reason, $\mathrm{NH}_{3}$, turbidity, chl $a$, and TKN may be better indicators of long-term temporal change due to small day-to-day variation.

\section{CONCLUSIONS}

Nutrients, turbidity, and chl a were useful indicators of spatial variation in coastal water quality. We further established that the temporal variability at each site occurred over short to moderate time frames. It is problematic that small-scale variability is so large on the scales of days for several nutrients, because these short-term fluctuations could potentially hamper the interpretation of patterns over longer time frames. In these cases, it may be possible to identify patterns in time as space by analysing several daily samples within a given time period (i.e. month) to obtain an average of those samples that could represent a mean for that place and time period. Alternatively, data could be analysed over longer time periods (e.g. several months to years of sampling a particular site), which would enable replication for time periods and places of interest.

In conclusion, we are becoming increasingly aware that the biological and physical parameters we study are complex at small temporal and spatial scales. This is particularly challenging to the demands put on environmental scientists who are expected to provide interpretations at much broader scales, particularly those useful to the scales of management (e.g. catchmentwide). By understanding scales of variation, we may be in a better position to provide reliable interpretations to managers if we can recognise the consequences of small-scale variation. Indeed, variation at local scales need not impede tests for broader-scale patterns (Fowler-Walker et al. 2005), but can be incorporated to improve the way we consider, gather, and interpret patterns in environmental data.

Acknowledgements. We thank J. P. Livore, J. Neumann, and M. E. Segade for field sampling. We thank members of the scientific advisory board from the Department for Environment and Heritage, National Land and Water Resources Audit of NRM groups. Valuable comments on previous version of this manuscript were provided by S. Gaylard. T.S.E. and S.D.C. were supported by ARC Fellowships, with funding from the Department for Environment and Heritage, South Australia, to the University of Adelaide.

\section{LITERATURE CITED}

ArandaCirerol N, Herrera-Silveira JA, Comín FA (2006) Nutrient water quality in a tropical coastal zone with groundwater discharge, northwest Yucatán, Mexico. Estuar Coast Shelf Sci 68:445-454

Babiker IS, Mohamed MAA, Komaki K, Ohta K, Kato K (2004) Temporal variations in the dissolved nutrient stocks in the surface water of the western North Atlantic Ocean. J Oceanogr 60:553-562

> Boyer JN, Fourqurean JW, Jones RD (1997) Spatial characterization of water quality in Florida Bay and Whitewater Bay by multivariate analyses: zones of similar influence. Estuaries 20:743-758

Boyle KA, Kamer K, Fong P (2004) Spatial and temporal patterns in sediment and water column nutrients in a eutrophic southern California estuary. Estuaries 27: 378-388

Brodie J, De'ath G, Devlin M, Furnas M, Wright M (2007) Spatial and temporal patterns of near-surface chlorophyll $a$ in the Great Barrier Reef lagoon. Mar Freshw Res 58:342-353

Buzzelli C, Akman O, Buck T, Koepfler E, Morris J, Lewitus A (2004) Relationships among water-quality parameters from the North Inlet-Winyah Bay National Estuarine Research Reserve, South Carolina. J Coast Res 45:59-74

Caffrey JM, Chapin TP, Jannasch HW, Haskins JC (2007) High nutrient pulses, tidal mixing and biological response in a small California estuary: variability in nutrient concentrations from decadal to hourly time scales. Estuar Coast Shelf Sci 71:368-380

Carr MH, Neigel JE, Estes JA, Andelman S, Warner RR, Largier JL (2003) Comparing marine and terrestrial ecosystems: implications for the design of coastal marine reserves. Ecol Appl 13(Suppl):90-107

Connell SD (2007) Water quality and the loss of coral reefs and kelp forests: alternative states and the influence of 
fishing. In: Connell SD, Gillanders BM (eds) Marine ecology. Oxford University Press, Melbourne, p 556-568

Connell SD, Russell BD, Turner DJ, Shepherd SA and others (2008) Recovering a lost baseline: missing kelp forests from a metropolitan coast. Mar Ecol Prog Ser 360:63-72

Cox EF, Ribes M, Kinzie RA III (2006) Temporal and spatial scaling of planktonic responses to nutrient inputs into a subtropical embayment. Mar Ecol Prog Ser 324:19-35

Dayton PK, Tegner MJ, Edwards PB, Riser KL (1998) Sliding baselines, ghosts, and reduced expectations in kelp forest communities. Ecol Appl 8:309-322

> De Galan S, Elskens M, Goeyens L, Pollentier A, Brion N, Baeyens W (2004) Spatial and temporal trends in nutrient concentrations in the Belgian Continental area of the North Sea during the period 1993-2000. Estuar Coast Shelf Sci 61:517-528

Edgar GJ, Bustamante RH, Fariña JM, Calvopiña M, Martínez C, Toral-Grande MV (2004) Bias in evaluating the effects of marine protected areas: the importance of baseline data for the Galapagos Marine Reserve. Environ Conserv 31:212-218

Ensign SH, Paerl HW (2006) Development of an unattended estuarine nutrient monitoring program using ferries as data-collection platforms. Limnol Oceanogr Methods 4: 399-405

EPA (Environmental Protection Authority) (2008) Water quality by body type. South Australia Environmental Protection Authority, Adelaide, available at www.epa.sa.gov.au/ water_type.html

Fock HO (2003) Changes in the seasonal cycle of inorganic nutrients in the coastal zone of the southeastern North Sea from 1960 to 1997: effects of eutrophication and sensitivity to meteoclimatic factors. Mar Pollut Bull 46:1434-1449

Fowler-Walker MJ, Connell SD, Gillanders BM (2005) Variation at local scales need not impede tests for broader scale patterns. Mar Biol 147:823-831

Gibbs MT (2000) Elevated chlorophyll a concentrations associated with a transient shelfbreak front in a western boundary current at Sydney, south-eastern Australia. Mar Freshw Res 51:733-737

Golterman HL, Clymo RS, Ohnstad MAM (1978) Methods for physical and chemical analysis of fresh waters. Blackwell Scientific, Oxford

Gorgula SK, Connell SD (2004) Expansive covers of turfforming algae on human-dominated coasts: the relative effects of increasing nutrient and sediment loads. Mar Biol 145:613-619

Gorman D, Russell BC, Connell SD (in press) Land-to-sea connectivity: linking habitat-derived terrestrial subsidies to subtidal habitat change on open rocky coasts. Ecol Appl

Gotelli NJ, Ellison AM (2004) A primer of ecological statistics. Sinauer Associates, Sunderland, MA

> Graham MH, Edwards MS (2001) Statistical significance versus fit: estimating the importance of individual factors in ecological analysis of variance. Oikos 93:505-513

Greene CM, Beechie TJ (2004) Consequences of potential density-dependent mechanisms on recovery of oceantype chinook salmon (Oncorhynchus tshawytscha). Can J Fish Aquat Sci 61:590-602

Grenz C, Cloern JE, Hager SW, Cole BE (2000) Dynamics of nutrient cycling and related benthic nutrient and oxygen

Editorial responsibility: Anne Hershey, Greensboro, North Carolina, USA fluxes during a spring phytoplankton bloom in South San Fransisco Bay (USA). Mar Ecol Prog Ser 197:67-80

Grotti M, Soggia F, Abelmoschi M, Rivaro P, Magi E, Frache R (2001) Temporal distribution of trace metals in Antarctic coastal waters. Mar Chem 76:189-209

Hatje V, Birch GF, Hill DM (2001) Spatial and temporal variability of particulate trace metals in Port Jackson estuary, Australia. Estuar Coast Shelf Sci 53:63-77

Huang XP, Huang LM, Yue WZ (2003) The characteristics of nutrients and eutrophication in the Pearl River estuary, South China. Mar Pollut Bull 47:30-36

- Humborg C, Danielsson Å, Sjöberg B, Green M (2003) Nutrient land-sea fluxes in oligothrophic and pristine estuaries of the Gulf of Bothnia, Baltic Sea. Estuar Coast Shelf Sci 56:781-793

- Huston MA (1999) Local process and regional patterns: appropriate scales for understanding variation in the diversity of plants and animals. Oikos 86:393-401

Li Y, Smayda TJ (2001) A chlorophyll time series for Narragansett Bay: assessment of the potential effect of tidal phase on measurement. Estuaries 24:328-336

Morrisey DJ, Underwood AJ, Howitt L, Stark JS (1992) Temporal variation in soft-sediment benthos. J Exp Mar Biol Ecol 164:233-245

> Morrisey DJ, Underwood AJ, Stark JS, Howitt L (1994) Temporal variation in concentrations of heavy metals in marine sediments. Estuar Coast Shelf Sci 38:271-282

> Neal C, Jarvie HP, Williams RJ, Pinder LCV, Collett GD, Neal M, Bhardwaj L (2000) The water quality of the Great Ouse. Sci Total Environ 251-252:423-440

> Pauly D (1995) Anecdotes and the shifting baseline syndrome of fisheries. Trends Ecol Evol 10:430

Potts PJ (1997) A glossary of terms and definitions used in analytical chemistry. Geostand Newsl 21:157-161

Quinn GP, Keough MJ (2002) Experimental design and data analysis for biologists, 1st edn. Cambridge University Press, Cambridge

Roberts CM, Branch G, Bustamante RH, Castilla JC and others (2003) Application of ecological criteria in selecting marine reserves and developing reserve networks. Ecol Appl 13(Suppl):215-228

Seuront L, Gentilhomme V, Lagadeuc Y (2002) Small-scale nutrient patches in tidally mixed coastal waters. Mar Ecol Prog Ser 232:29-44

Underwood AJ (1997) Experiments in ecology: their logical design and interpretation using analysis of variance. Cambridge University Press, Cambridge

Underwood AJ, Petraitis PS (1993) Structure of intertidal assemblages in different locations: How can local processes be compared? In: Ricklefs $\mathrm{R}$, Schluter D (eds) Species diversity in ecological communities. University of Chicago Press, Chicago, IL, p 38-51

Vaughan GM, Corballis MC (1969) Beyond tests of significance: estimating strength of effects in selected ANOVA designs. Psychol Bull 72:204-213

Wetzel RG (1983) Limnology, 2nd edn. Saunders College Publishing, New York

White DL, Porter DE, Leqitus AJ (2004) Spatial and temporal analyses of water quality and phytoplankton biomass in an urbanized versus a relatively pristine salt marsh estuary. J Exp Mar Biol Ecol 298:255-273

Submitted: November 14, 2008; Accepted: February 22, 2009 Proofs received from author(s): March 25, 2009 